\title{
Spectrophotometric determination of hydrogen sulfide in environmental samples using sodium 1,2-naphthoquinone-4- sulfonate and response surface methodology
}

\author{
M. Shariati-Rad ${ }^{1} \cdot$ M. Irandoust ${ }^{1} \cdot$ F. Jalilvand ${ }^{1}$
}

Received: 19 September 2015/Revised: 6 February 2016/ Accepted: 10 February 2016/Published online: 3 March 2016

(C) Islamic Azad University (IAU) 2016

\begin{abstract}
A simple spectrophotometric method for determination of hydrogen sulfide in wastewater and hot spring samples was developed. The method is based on the reaction between hydrogen sulfide and sodium 1,2-naphthoquinone-4-sulfonate (NQS). The effect of various experimental factors on the reaction between hydrogen sulfide and NQS was investigated and optimized using central composite design. The optimal values of the factors were $5.00 \times 10^{-4} \mathrm{~mol} \mathrm{~L}^{-1}$ for concentration of NQS and $1.00 \times 10^{-2} \mathrm{~mol} \mathrm{~L}^{-1}$ for concentration of hydrochloric acid. The wavelength of the maximum absorption of the reaction product was $320 \mathrm{~nm}$. Constructed calibration curve for hydrogen sulfide determination was linear in the range of $0.5-20.0 \mathrm{mg} \mathrm{L}^{-1}$ with the detection limit of $0.16 \mathrm{mg} \mathrm{L}^{-1}$. The method was free from interferences. Percent relative errors below $2 \%$ were obtained for determination of hydrogen sulfide in environmental samples.
\end{abstract}

Keywords Hydrogen sulfide · 1,2-naphthoquinone-4sulfonate $\cdot$ Central composite design $\cdot$ Environmental

\section{Introduction}

Water pollutants are of great public concern, and removal of them is of great importance (Gupta et al. 2012, 2013; Gupta and Saleh 2013; Saleh and Gupta 2011, 2012a, b, c; Saleh 2011).

M. Shariati-Rad

mshariati_rad@yahoo.com

1 Department of Analytical Chemistry, Faculty of Chemistry, Razi University, Kermanshah, Iran
Hydrogen sulfide is gaseous molecule that accumulates in the environment from geothermal and anthropogenic sources (Watts 2000). In environmental waters, decomposition of organic matter and the activity of sulfate-reducing bacteria lead to the formation of hydrogen sulfide (Patnaik 1999; Yao and Millero 1996). This gas is a very important pollution index for water (Colon et al. 2008). It exists naturally in crude petroleum, natural gas, hot springs and foods. Furthermore, it is also produced in large quantity in industrial activities and places such as petroleum/natural gas drilling and refining, wastewater treatment, coke ovens, tanneries, Kraft paper mills and landfills (Kim et al. 2005, 2006). Exposure to this colorless, flammable gas can trigger eye and respiratory tract irritation (Evans 1967). Therefore, easy, inexpensive and convenient signaling of toxic hydrogen sulfide is very important for the rapid assessment of this widely used and environmentally important species. Various analytical techniques for the detection of hydrogen sulfide have been reviewed (Lawrence et al. 2000; Pandey et al. 2012).

A standard method for detection and determination of hydrogen sulfide is gas chromatography (Hannestad et al. 1989; Furne et al. 2008; Pandey and Kim 2009). However, application of these methods is not simple and includes several stages. Hence, relatively simpler methods such as titration (Balasubramanian and Pugalenthi 2000), spectrophotometry (Evans 1967; Ferrer et al. 2004; Silva et al. 2001, 2003; Rodriguez-Fernandez et al. 1999; Kuban et al. 1992; Siegel 1965; Fischer 1883) and spectrofluorimetry (Rodriguez-Fernandez et al. 1999; Choi and Hawkins 1997; Axelrod et al. 1969; Spaziani et al. 1997; Gohda et al. 1986; Yang et al. 2000) have been introduced for this purpose.

In these conditions, more advanced instrumental methods have also been developed for determination of hydrogen sulfide like inductively coupled plasma-atomic 
emission spectroscopy (Pouly et al. 1999), hydride generation-atomic fluorescence spectrometry (Jin et al. 2007), electrochemistry (Lawrence et al. 2004; Spilker et al. 2008; Tsai et al. 2006; García-Calzada et al. 1999; He et al. 2002; Doeller et al. 2005), ion chromatography (Giuriati et al. 2004; Divjak and Goessler 1999) and chemiluminescence (Lawrence et al. 2000; Huang et al. 2007; Maya et al. 2007; Safavi and Karimi 2002; Du et al. 2001). However, development of simple methods which does not require sophisticated instruments is a permanent requirement.

In the present work, a simple spectrophotometric method for determination of hydrogen sulfide is proposed. 1,2-Naphthoquinone-4-sulfonate was used as reagent in acidic medium. This reagent has functional groups (Quinone) which can be reduced by hydrogen sulfide. The factors influencing the reaction were explored by response surface methodology.

\section{Materials and methods}

\section{Apparatus}

Recording of the absorption spectra in the spectral range of 200-500 nm was performed by an Agilent 8453 UV-Vis spectrophotometer with diode array detector, equipped with $1-\mathrm{cm}$ path-length quartz cells. A Huber polystat model CC3 thermostat was employed for temperature control. A JENWAY ion-meter, Model 3345 was employed for adjusting $\mathrm{pH}$.

\section{Reagents and solutions}

All of the chemicals used including sodium 1,2-naphthoquinone-4-sulfonate (NQS) and hydrochloric acid (Merck, Darmstadt, Germany) and sodium sulfide (BDH chemicals Ltd Poole England) were of analytical reagent grade and used as received without any further purification. Aqueous solutions were prepared in deionized water.

A $1.0 \times 10^{-3} \mathrm{~mol} \mathrm{~L}^{-1}$ stock solution of NQS was prepared by appropriate amount of solid in deionized water. NQS solutions were freshly prepared for experiment any stage. A $10 \mathrm{~mL}$ stock solution of sodium sulfide with concentration of $500.0 \mathrm{mg} \mathrm{L}^{-1}$ was prepared in deionized water. For preparation of acidic solutions, appropriate volume of the concentrated hydrochloric acid $\left(12.7 \mathrm{~mol} \mathrm{~L}^{-1}\right)$ was diluted by doubly deionized water.

\section{Response surface methodology}

Experimental design is a strategy to gather empirical knowledge based on the analysis of experimental data and not on theoretical models. An effective experimental design technique commonly used for process analysis and modeling is central composite design (CCD). For a given number of factors $(f)$, this design is a combination of a twolevel full factorial design with $2^{f}$ points, $2 f$ axial points and N0 central points.

The central point for each factor is assumed to be middle of the two levels of the full factorial points, around which the design is supposed to be symmetric. The factors considered for the studied system are concentration of NQS $\left(x_{1}\right)$ and concentration of hydrochloric acid $\left(x_{2}\right)$ in $\mathrm{mol} \mathrm{L}^{-1}$. The low and high levels of these factors are 0.0001 and $0.0005 \mathrm{~mol} \mathrm{~L}^{-1}$ for NQS and 0.001 and $1.000 \mathrm{~mol} \mathrm{~L}^{-1}$ for hydrochloric acid. For a system with two factors $(f=2), \mathrm{CCD}$ can be represented by points on a square, in which each axis corresponds to a factor and consists of 13 points (four full factorial points, four axial points and five arbitrary central points). Values of the factors in these thirteen experiments and obtained responses are shown in Table 1.

\section{Procedure for calibration}

A volume equivalent to $2.50 \mathrm{~mL}$ of the stock solution of NQS, $0.50 \mathrm{~mL}$ of hydrochloric acid solution with concentration of $0.1 \mathrm{~mol} \mathrm{~L}^{-1}$ and different concentrations of sodium sulfide were transferred into $5-\mathrm{mL}$ volumetric flasks. Then, the mixtures were completed to the mark with deionized water. The mixture was mixed well, and the reaction was allowed to proceed at room temperature $\left(25.00 \pm 1{ }^{\circ} \mathrm{C}\right)$ for $60 \mathrm{~min}$. The absorbance of the resulting solutions was measured against a reagent blank prepared with the same reagents concentration, but no sodium sulfide.

\section{Sample preparation for determination of hydrogen sulfide in different water samples}

All of the analyzed water samples (wastewater and hot spring) were collected and were filtered through a Whatman No. 41 filter paper, and the filtrates were transferred into $100-\mathrm{mL}$ volumetric flask without dilution. In the analysis of the hot spring samples, after sampling, zinc acetate was added to the sample to trap hydrogen sulfide as zinc sulfide precipitate. For the analysis and releasing hydrogen sulfide in hot spring samples, $\mathrm{pH}$ of the sample was adjusted to 1.0 by adding hydrochloric acid and the sample was filtered and transferred into a $100-\mathrm{mL}$ volumetric flask without dilution.

For the analysis of the real samples, a volume equivalent to $2.50 \mathrm{~mL}$ of the stock solution of NQS and $0.50 \mathrm{~mL}$ of hydrochloric acid solution with concentration of $0.1 \mathrm{~mol} \mathrm{~L}^{-1}$ were transferred into 5 -mL volumetric flasks. The mixture was then completed to the mark with the 
Table 1 Experiments based on the central composite design with two factors

\begin{tabular}{llll}
\hline Experiment number & $\begin{array}{l}\text { NQS concentration } \\
\left(\mathrm{mol} \mathrm{L}^{-1}\right)\end{array}$ & $\begin{array}{l}\text { Concentration of hydrochloric } \\
\text { acid }\left(\mathrm{mol} \mathrm{L}^{-1}\right)\end{array}$ & $\begin{array}{l}\text { Response (absorbance } \\
\text { change at 320 nm) }\end{array}$ \\
\hline 1 & 0.00030 & 0.50050 & 0.579 \\
2 & 0.00010 & 1.00000 & 0.327 \\
3 & 0.00050 & 0.00100 & 0.682 \\
4 & 0.00050 & 1.00000 & 0.604 \\
5 & 0.00030 & 0.50050 & 0.468 \\
6 & 0.00030 & 0.00000 & 0.357 \\
7 & 0.00030 & 0.50050 & 0.421 \\
8 & 0.00030 & 0.50050 & 0.480 \\
9 & 0.00006 & 0.50050 & 0.254 \\
10 & 0.00030 & 1.09990 & 0.469 \\
11 & 0.00030 & 0.50050 & 0.564 \\
12 & 0.00010 & 0.00100 & 0.000 \\
13 & 0.00054 & 0.50050 & 0.411 \\
\hline
\end{tabular}

above real samples, and after $60 \mathrm{~min}$, its spectrum was recorded. For spiking, after addition of different concentrations of standard sodium sulfide solution, the real sample was added to the mixture.

For each sample, five replicates were measured and mean of the predicted concentrations was reported. Based on these replicates, standard deviation was calculated and divided by mean of the results to yield percent relative standard deviation (RSD\%) after multiplication by 100 . Percent relative error (RE\%) was obtained by dividing the difference between the predicted amount and actual amount to the actual amount multiplied by 100. Multiplication of the ratio of predicted amount to the actual amount by 100 will give percent recovery.

\section{Results and discussion}

Due to the leachability of sodium sulfide as hydrogen sulfide with time, the reagent grade sodium sulfide must firstly be standardized. In the second step, the condition of the reaction between NQS and hydrogen sulfide should be optimized. In the optimal conditions, the reaction was employed to build a relation between the signal and hydrogen sulfide concentration.

In the next step, the constructed calibration was used to determine hydrogen sulfide in the environmental samples. In the last part of the work, the characteristics of the method were compared with the related published works.

\section{Standardization of sodium sulfide stock solution}

A volume equivalent to $2.0 \mathrm{~mL}$ of freshly prepared sodium sulfide reagent solution with concentration of
$500.0 \mathrm{mg} \mathrm{L}^{-1}$ was transferred into a conical flask. After adding $5.0 \mathrm{~mL}$ of a standard iodate solution $\left(0.005 \mathrm{~mol} \mathrm{~L}^{-1}\right)$, and $0.291 \mathrm{~g}$ potassium iodide $(\mathrm{KI})$, the solution was acidified with $0.5 \mathrm{~mL}$ of sulfuric acid, the solution was allowed to stand for $10 \mathrm{~min}$, and excess of the iodine was titrated by standard sodium thiosulfate solution. Starch solution was added when the color of the solution became pale straw. After addition of starch solution, immediately the color was changed to deep blue-black. The titration was continued until the color changes from deep blue-black to colorless. Similarly, the blank titration was performed. The difference between titration values of the blank and sample was used for calculation of sodium sulfide contents in stock solution. Calculations based on the results of titration revealed that the purity of the reagent sodium sulfide solution is $28.8 \%$.

\section{Reaction between hydrogen sulfide and NQS}

In acidic media, sulfide is considerably in the form of hydrogen sulfide. It can be simply realized from the $p K a_{1}$ and $p \mathrm{Ka}_{2}$ values of hydrogen sulfide (7.02 and 13.88, respectively). In a solution with concentration of hydronium ion close to $0.1 \mathrm{~mol} \mathrm{~L}^{-1}$, more than $99.99 \%$ of the sulfide is in the form of hydrogen sulfide.

In the reaction with NQS, hydrogen sulfide reduces the carbonyl groups of NQS to hydroxyl ones. To prove this change, FTIR spectrum of NQS and the product of its reaction with hydrogen sulfide were recorded (Fig. 1). As can be seen in the spectrum of the product (Fig. 1b), broad band at $3505 \mathrm{~cm}^{-1}$ has been evolved. This band is the characteristics of the stretching of the $\mathrm{O}-\mathrm{H}$ bond (Gupta et al. 2011a, b; Saleh 2015a, b; Saleh et al. 2014). It can be noted that this band cannot be seen in the FTIR 

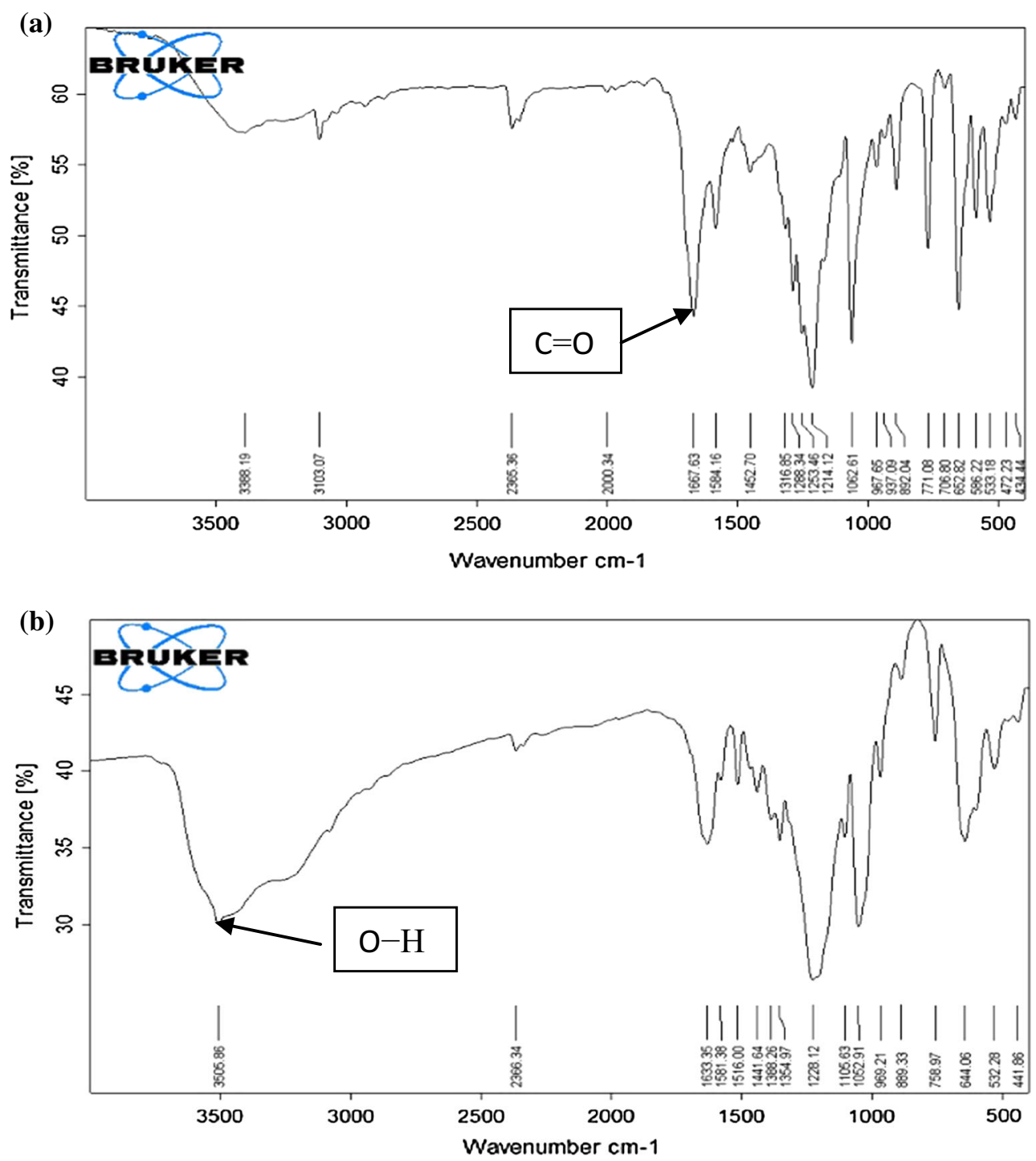

Fig. 1 FTIR spectrum of a NQS in hydrochloric acid medium and $\mathbf{b}$ NQS in the presence of hydrogen sulfide

spectrum of NQS (Fig. 1a). In aryl ketones, the stretching of the $\mathrm{C}=\mathrm{O}$ occurs at $1680-1700 \mathrm{~cm}^{-1}$ (Saleh $2015 \mathrm{a}$, b; Saleh et al. 2011). For NQS, this band has been shifted to the lower wavelengths and can be seen at $1668.64 \mathrm{~cm}^{-1}$ (Fig. 1a). However, as can be seen in Fig. 1b, the intensity of this band has been decreased. Moreover, diketones have characteristics at $1540-1640 \mathrm{~cm}^{-1}$ (Gupta et al. 2011a, b) which can be simply observed in Fig. 1a. It can clearly be observed in Fig. 1 that the peak located at $1668.64 \mathrm{~cm}^{-1}$ decreases in intensity accompanying by the evolving the band at $3505 \mathrm{~cm}^{-1}$ assigned to $\mathrm{O}-\mathrm{H}$ bond. This indicates the reaction between NQS and hydrogen sulfide.

Based on the inspection of the FTIR spectra, the reaction between hydrogen sulfide and NQS can be shown as in Scheme 1. Hydrogen sulfide acts as a reducing agent, and<smiles>O=C1C=C(S(=O)(=O)O)c2ccccc2C1=O</smiles>

Scheme 1 Proposed reaction between NQS and hydrogen sulfide

carbonyl groups are reduced to hydroxyl groups. Sulfur can be considered as another product of the reaction.

\section{Absorption spectra}

In Fig. 2, the absorbance spectra of NQS in acidic medium and in the presence of hydrogen sulfide in optimal 


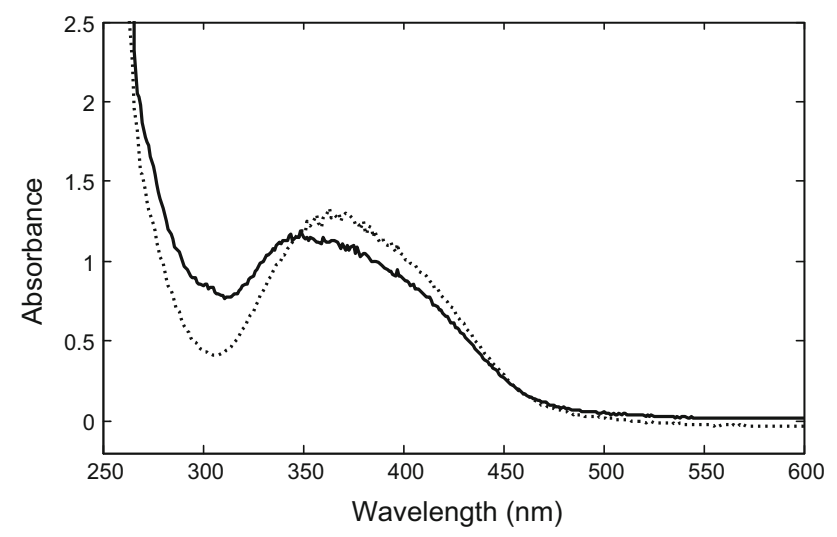

Fig. 2 Absorbance spectrum of NQS $\left(5.00 \times 10^{-4} \mathrm{~mol} \mathrm{~L}^{-1}\right)$ in hydrochloric acid $\left(1.0 \times 10^{-2} \mathrm{~mol} \mathrm{~L}^{-1}\right.$; dotted line $)$ and NQS $\left(5.00 \times 10^{-4} \mathrm{~mol} \mathrm{~L}^{-1}\right)$ in hydrochloric acid $\left(1.0 \times 10^{-2} \mathrm{~mol} \mathrm{~L}^{-1}\right)$ in the presence of hydrogen sulfide $\left(5.00 \mathrm{mg} \mathrm{L}^{-1}\right.$; solid line)

conditions are shown. Wavelength of the maximum absorption of the product is located at $320 \mathrm{~nm}$.

NQS possess a broad absorption peak with maximum located at about $360 \mathrm{~nm}$ (Fig. 2). In the presence of hydrogen sulfide, maximum of this absorption peak shifts to $345 \mathrm{~nm}$. Moreover, a new peak at about $320 \mathrm{~nm}$ appears. Upon addition of hydrogen sulfide to the solution of NQS in optimal conditions, a decrease in absorbance at $360 \mathrm{~nm}$ and an increase in absorbance at $320 \mathrm{~nm}$ can be seen.

\section{Response surface methodology (RSM) and optimization of factors}

Response surface methodology (RSM) is a method of experimental design used for the optimization of chemical reactions and/or industrial processes. Whenever several factors influence the response, RSM can be utilized to assess the relationship between dependent (response) and independent variables (factors) as well as to optimize the relevant processes. Experimental design methodology involves simultaneous changing the level of all the factors from one experiment to the next because the factors can influence each other, and the optimal value for one of the factor might be related to the values of the others. CCD as a response surface method was originally developed by Box et al. (1951) and later on improved upon by Box and Hunter (1957).

In Table 1, the responses of the experiments designed based on CCD have been included. The closeness of the responses of the replicate experiments (experiments 1, 5, 7, 8 and 11 in Table 1) is the sign of the precision of the experiment process. The relation between the response and the factors can be shown by the following polynomial equation:
Table 2 Results of ANOVA for the experiments and responses reported in Table 1

\begin{tabular}{lclr}
\hline Term & Coefficient & $p^{\mathrm{a}}$ & $F^{\mathrm{b}}$ \\
\hline Constant & 0.494 & 0.000 & \\
$x_{1}$ & 0.167 & 0.004 & 17.11 \\
$x_{2}$ & 0.056 & 0.210 & 1.91 \\
$x_{1} x_{1}$ & -0.086 & 0.127 & 2.99 \\
$x_{2} x_{2}$ & -0.031 & 0.556 & 0.38 \\
$x_{1} x_{2}$ & -0.101 & 0.096 & 3.69 \\
Regression & & 0.025 & 5.25 \\
$R$ & 0.888 & & \\
\hline
\end{tabular}

a Probability value

${ }^{\mathrm{b}} F$ statistics

Response $=b_{0}+b_{1} x_{1}+b_{2} x_{2}+b_{11} x_{1} x_{1}+b_{22} x_{2} x_{2}+b_{12} x_{1} x_{2}$

where $b_{0}$ is the average of the results of the replicated center point. The coefficients $b_{1}$ and $b_{2}$ are the main halfeffects of the variables $x_{1}$ and $x_{2}$, respectively. $b_{11}$ and $b_{22}$ are the squared effects, and $b_{12}$ is the two-factor interaction effect.

Analysis of variance (ANOVA) of the experiments (Table 1) is given in Table 2. The regression between the response and factors (model) is reliable due to the high correlation coefficient $(R=0.888)$ and very low $p$ value $(0.025)$ of the regression. This $p$ value indicates that the variation in the response is mainly (about $88.8 \%$ ) due to the variation in the factor levels. Among the linear terms, the concentration of NQS $\left(x_{1}\right)$ is highly significant. This is reflected in the very low calculated $p$ value $(0.004)$ and high $F$ statistics (17.11). Interaction between the studied factors is relatively important. This can be realized from the calculated $p$ value for the term $x_{1} x_{2}$ in Table 2. None of the squared terms is significant at the $95 \%$ confidence level since corresponding $p$ values are high.

After performing ANOVA, the response surface of the full quadratic model was depicted. Via the surface, the relations between the response and the effective factors are graphically shown. The surface is shown in Fig. 3. The surface shows that for maximizing response, in the low levels of $x_{2}$ (concentration of hydrochloric acid), higher amounts of $x_{1}$ (concentration of NQS) is needed. On the other hand, when concentration of hydrochloric acid increases, the response is higher at moderate levels of concentration of NQS. This is the concept of the interaction between the factors which was realized by considering $p$ values in the preceding paragraph. The optimal value for each factor which leads to the best response (the highest absorbance intensity) can be extracted from response surface. The response optimizer was used to give the values of the factors for which the response is higher. The result is 


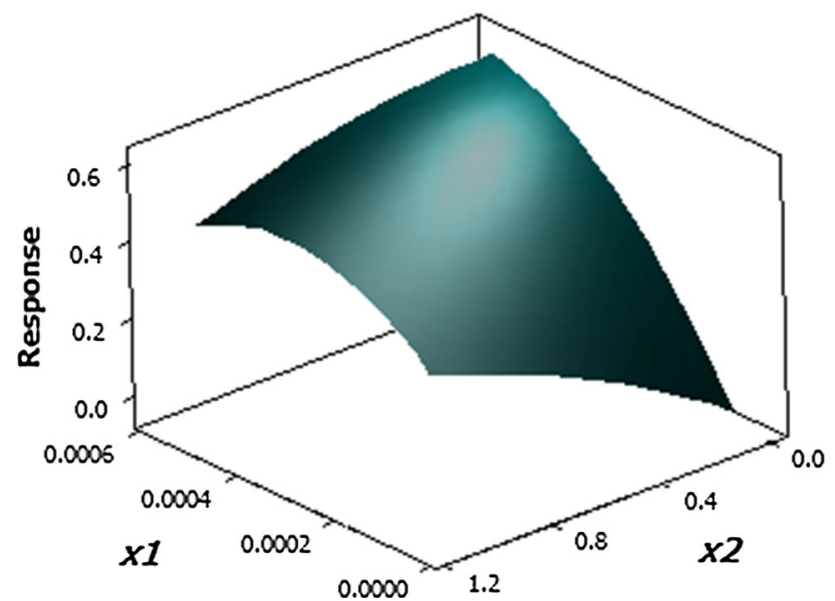

Fig. 3 Response surface obtained by the model with coefficients reported in Table 2 and factors $x_{1}$ (concentration of NQS) and $x_{2}$ (concentration of hydrochloric acid)

$5.00 \times 10^{-4} \mathrm{~mol} \mathrm{~L}^{-1}$ for $x_{1}$ and $1.00 \times 10^{-2} \mathrm{~mol} \mathrm{~L}^{-1}$ for $x_{2}$.

The coefficient of the concentration of NQS $\left(x_{1}\right)$ is positive (Table 2), and it is the largest coefficient in Table 2 except for the constant term. This indicates the importance of the concentration of NQS in the studied reaction. From Fig. 3, the significant effect of concentration of NQS $\left(x_{1}\right)$ on the response is clearly observed. The coefficient of concentration of hydrochloric acid $\left(x_{2}\right)$ is positive, but it is smaller than the coefficient for $x_{1}$. Therefore, $x_{2}$ is not as important as the concentration of NQS in the studied reaction. This can be simply inferred from Fig. 3.

\section{Analytical data}

In order to examine the applicability of the recommended method for determination of hydrogen sulfide, the absorbance of a series of solutions containing varying concentrations of hydrogen sulfide in the optimal conditions was recorded against the corresponding reagent blank at $320 \mathrm{~nm}$. The univariate calibration curve was linear in the range of $0.50-20.00 \mathrm{mg} \mathrm{L}^{-1}$. The statistical parameters of the constructed calibration curve are summarized in Table 3. As data in Table 3 show, the linear range of the method for determination of hydrogen sulfide is relatively wide.

\section{Application to the real samples}

Before application of the proposed method for determination of hydrogen sulfide in real environmental samples, leachability tests were done for hydrogen sulfide. For this
Table 3 Statistical results of the calibration of hydrogen sulfide using the proposed method

\begin{tabular}{ll}
\hline Parameters & Characteristic \\
\hline Color changes & Yellow to colorless \\
Wavelength (nm) & 320 \\
Molar absorptivity $\left(\mathrm{L} \mathrm{mol}^{-1} \mathrm{~cm}^{-1}\right)$ & $1.4 \times 10^{3}$ \\
Linear range $\left(\mathrm{mg} \mathrm{L}^{-1}\right)$ & $0.50-20.00$ \\
Number of samples & 11 \\
Intercept of calibration curve & 0.0114 \\
Slope of calibration curve & 0.0456 \\
Correlation coefficient & 0.997 \\
F statistic of the model & 1642.68 \\
Limit of detection $\left(\mathrm{mg} \mathrm{L}^{-1}\right)^{\mathrm{a}}$ & 0.16
\end{tabular}

${ }^{\text {a }}$ Calculated as DL $=3 s_{\mathrm{B}} / m, s_{\mathrm{B}}$ is the standard deviation of the blank and $m$ is the slope of the calibration curve

purpose, different $10.0 \mathrm{mg} \mathrm{L}^{-1}$ solutions of hydrogen sulfide were prepared and after times $0,1,2,3$ and $4 \mathrm{~h}$, in optimal conditions, corresponding spectra were recorded. Based on the absorbances and calibration curve, the concentration of hydrogen sulfide was calculated. The results showed that in average, $11.8 \%$ of the hydrogen sulfide is lost per hour.

In order to examine the suitability of the recommended method for determination of hydrogen sulfide in real samples, it was applied to wastewater and hot spring samples. Application of the method showed that the examined samples have amounts of hydrogen sulfide. However, the hot spring sample has considerable amounts of hydrogen sulfide. Accuracy was evaluated as the percent relative error in prediction (RE\%), and precision was evaluated by percent relative standard deviation (RSD\%). The results of the analyses have been collected in Table 4 . As can be inferred from data in Table 4, the method for determination of hydrogen sulfide in different samples is very accurate (RE\% values are below $2 \%$ ). Moreover, this indicates that the method is very selective.

\section{Interference study}

Validity of the method was assessed by examining the effect of various anions and cations at $\mathrm{mg} \mathrm{L}^{-1}$ levels on the determination of hydrogen sulfide using the recommended method. These studies were performed in the optimal values of the factors. The results have been collected in Table 5. The anions were used as sodium and potassium salts, and the cations as chlorides and nitrate. As can be seen from Table 5, most of the common anions do not interfere in determination of hydrogen sulfide. Among 
Table 4 Application of the recommended method for determination of hydrogen sulfide in various samples
Table 5 Effect of interfering ions on the determination of hydrogen sulfide

\begin{tabular}{llllll}
\hline Sample & $\begin{array}{l}\text { Hydrogen Sulfide } \\
\text { added }\left(\mathrm{mg} \mathrm{L}^{-1}\right)\end{array}$ & $\begin{array}{l}\text { Hydrogen Sulfide } \\
\text { found }\left(\mathrm{mg} \mathrm{L}^{-1}\right)\end{array}$ & $\operatorname{RSD}(\%)^{\mathrm{a}}$ & $\operatorname{RE}(\%)^{\mathrm{b}}$ & Recovery $(\%)^{\mathrm{c}}$ \\
\hline Wastewater & 0.00 & 2.62 & 5.5 & -0.51 & 99.5 \\
& 2.00 & 4.61 & & & \\
\multirow{2}{*}{ Hot spring } & 0.00 & 14.55 & 3.3 & 1.85 & 98.1 \\
& 2.00 & 16.52 & & & \\
\hline
\end{tabular}

Number of replicates for calculation of RSD\% and RE\% is five

${ }^{a}$ Percent relative standard deviation (RSD\%) was calculated by dividing the standard deviation of the five repetition to the mean value of the predicted amount multiplied by 100

b Percent relative error (RE\%) was calculated by dividing the difference between the predicted amount and the actual amount to the actual amount multiplied by 100

${ }^{c}$ Percent recovery was obtained by dividing the predicted amount to the actual amount multiplied by 100

\begin{tabular}{|c|c|c|c|}
\hline Foreign ions & Added as & Error & Tolerance limit $\left(\mathrm{mg} \mathrm{L}^{-1}\right)$ \\
\hline $\mathrm{CN}^{-}$ & $\mathrm{KCN}$ & -13.2 & 5 \\
\hline $\mathrm{CH}_{3} \mathrm{COO}^{-}$ & $\mathrm{CH}_{3} \mathrm{COONa} \cdot 3 \mathrm{H}_{2} \mathrm{O}$ & -11.2 & 5 \\
\hline $\mathrm{SO}_{3}{ }^{2-}$ & $\mathrm{Na}_{2} \mathrm{SO}_{3}$ & -13.2 & 10 \\
\hline $\mathrm{S}_{2} \mathrm{O}_{3}{ }^{2-}$ & $\mathrm{Na}_{2} \mathrm{~S}_{2} \mathrm{O}_{3} \cdot 5 \mathrm{H}_{2} \mathrm{O}$ & -8.8 & 10 \\
\hline $\mathrm{HCO}_{3}{ }^{-}$ & $\mathrm{NaHCO}_{3}$ & -15.3 & 20 \\
\hline $\mathrm{C}_{2} \mathrm{O}_{4}{ }^{2-}$ & $\mathrm{Na}_{2} \mathrm{C}_{2} \mathrm{O}_{4}$ & 9.2 & 30 \\
\hline $\mathrm{PO}_{4}{ }^{3-}$ & $\mathrm{K}_{3} \mathrm{PO}_{4} \cdot 3 \mathrm{H}_{2} \mathrm{O}$ & 9.3 & 50 \\
\hline $\mathrm{IO}_{3}^{-}$ & $\mathrm{KIO}_{3}$ & -9.5 & 50 \\
\hline $\mathrm{H}_{2} \mathrm{PO}_{4}^{-}$ & $\mathrm{KH}_{2} \mathrm{PO}_{4}$ & 10.6 & 80 \\
\hline $\mathrm{SO}_{4}{ }^{2-}$ & $\mathrm{Na}_{2} \mathrm{SO}_{4}$ & -10.1 & 100 \\
\hline $\mathrm{NO}_{3}^{-}$ & $\mathrm{KNO}_{3}$ & 5.3 & 200 \\
\hline $\mathrm{NO}_{2}^{-}$ & $\mathrm{KNO}_{2}$ & -5.6 & 200 \\
\hline $\mathrm{CO}_{3}^{2-}$ & $\mathrm{Na}_{2} \mathrm{CO}_{3}$ & 3.9 & 250 \\
\hline $\mathrm{Cl}^{-}$ & $\mathrm{LiCl}$ & -2.3 & 400 \\
\hline $\mathrm{Mg}^{2+}$ & $\mathrm{Mg}\left(\mathrm{NO}_{3}\right)_{2} \cdot 6 \mathrm{H}_{2} \mathrm{O}$ & -10.2 & 15 \\
\hline $\mathrm{Fe}^{2+}$ & $\mathrm{Fe}\left(\mathrm{NO}_{3}\right)_{2} \cdot 6 \mathrm{H}_{2} \mathrm{O}$ & 7.1 & 60 \\
\hline
\end{tabular}

Table 6 Comparison of the spectrophotometric methods for determination of hydrogen sulfide with the recommended method

\begin{tabular}{|c|c|c|c|c|}
\hline $\begin{array}{l}\text { Instrumental } \\
\text { methodology }\end{array}$ & Reagents & $\begin{array}{l}\text { Determination range } \\
\left(\mu \mathrm{mol} \mathrm{L}{ }^{-1}\right)\end{array}$ & $\begin{array}{l}\text { Detection limit } \\
\left(\mu \mathrm{mol} \mathrm{L}^{-1}\right)\end{array}$ & References \\
\hline Spectrofluorimetry & 2,4-Dinitrobenzenesulfonyl & $0.05-1$ & 0.0043 & Yang et al. (2009) \\
\hline Spectrophotometry & Hydrogen peroxide & $0.6-7.0$ & 0.4 & Ghadiri et al. (2013) \\
\hline Spectrofluorimetry & Dansyl azide & $0-100$ & As low as 1 & Peng et al. (2011) \\
\hline $\begin{array}{l}\text { Kinetic } \\
\text { spectrophotometric }\end{array}$ & Magenta & $0.735-73.52$ & 0.441 & $\begin{array}{l}\text { Safavi and Ramezani } \\
\text { (1997) }\end{array}$ \\
\hline Spectrofluorimetry & Iminocoumarin benzothiazole scaffold & $0-100$ & 0.15 & Zhang et al. (2015) \\
\hline Colorimetry & Nitrobenzoxadiazole moiety & $10-100$ & 2.1 & Bae et al. (2013) \\
\hline ICP-OES & - & $1.764-647$ & 0.882 & Cmelik et al. (2010) \\
\hline UV spectrophotometry & Silver nitrate & $14.7-441.17$ & 14.7 & Evans (1967) \\
\hline Spectrophotometry & $\begin{array}{l}N, N \text {-dimethyl- } p \text {-phenylene diamine } \\
\text { hydrochloride }\end{array}$ & $1.47-58.82$ & 1176.47 & Silva et al. (2001) \\
\hline Spectrophotometry & NQS & $15.6-625.0$ & 5.0 & This work \\
\hline
\end{tabular}


the examined species, very reactive anions such as $\mathrm{CN}^{-}$, $\mathrm{IO}_{3}{ }^{-}, \mathrm{S}_{2} \mathrm{O}_{3}{ }^{2-}$ and $\mathrm{NO}_{2}{ }^{-}$can be seen. As the results collected in Table 5 show, in most cases, the tolerance limit is high which indicates that the method is selective.

\section{Comparison with the published results}

We compared the results of some of the spectrophotometric methods (Yang et al. 2009; Ghadiri et al. 2013; Peng et al. 2011; Safavi and Ramezani 1997; Zhang et al. 2015; Bae et al. 2013; Cmelik et al. 2010; Evans 1967; Silva et al. 2001) for determination of hydrogen sulfide (Table 6). The linear range of the method presented here is satisfactory and relatively wide. We used simple and available reagents, and in this method we broadened the linear range of the calibration. The upper limit of the linear range of this method is better than other methods.

A method with a wide linear range is preferred. This is because it can be applied to different samples with a wide range of concentrations of the analyte (here hydrogen sulfide). Moreover, the method is simple which can be employed in most of the libraries.

\section{Conclusion}

Sodium 1,2-naphthoquinone-4-sulfonate (NQS) was introduced as a reagent for determination of hydrogen sulfide. The developed method is simple for determination of hydrogen sulfide. Hydrogen sulfide in acidic conditions reduces NQS which results in the changing color from yellow to colorless. The method was successfully applied to determine hydrogen sulfide in environmental water samples with very low relative errors. The most distinctive characteristic of the method is its wide linear range which makes it suitable for determination of hydrogen sulfide in various samples.

Acknowledgments The authors acknowledge the Razi University Research Council for support of this work.

\section{References}

Axelrod HD, Cary JH, Bonelli JE, Lodge JP Jr (1969) Fluorescence determination of sub-parts-per-billion hydrogen sulfide in the atmosphere. Anal Chem 41:1856-1858

Bae J, Gil Choi M, Choi J, Chang S-K (2013) Colorimetric signaling of hydrogen sulfide by reduction of a phenylseleno-nitrobenzoxadiazole derivative. Dyes Pigments 99:748-752
Balasubramanian S, Pugalenthi V (2000) A comparative study of the determination of sulphide in tannery waste water by ion selective electrode (ISE) and iodimetry. Water Res 34:4201-4206

Box GEP, Hunter JS (1957) Multi-factor experimental designs for exploring response surfaces. Ann Math Stat 28:195-241

Box GEP, Wilson KB, Roy J (1951) On the experimental attainment of optimum conditions. Stat Soc Ser B Method 13:1-45

Choi MF, Hawkins P (1997) Development of sulphide-selective optode membranes based on fluorescence quenching. Anal Chim Acta 344:105-110

Cmelik J, Machat J, Otruba V, Kanicky V (2010) Contribution to vapor generation-inductively coupled plasma spectrometric techniques for determination of sulfide in water samples. Talanta 80:1777-1781

Colon M, Todol JL, Hidalgo M, Iglesias M (2008) Development of novel and sensitive methods for the determination of sulfide in aqueous samples by hydrogen sulfide generation-inductively coupled plasma-atomic emission spectroscopy. Anal Chim Acta 609:160-168

Divjak B, Goessler W (1999) Ion chromatographic separation of sulfur-containing inorganic anions with an ICP-MS as elementspecific detector. J Chromatogr A 844:161-169

Doeller JE, Isbell TS, Benavides G, Koenitzer J, Patel H, Patel RP, Lancaster JR, Darley-Usmar VM, Kraus DW (2005) Polarographic measurement of hydrogen sulfide production and consumption by mammalian tissues. Anal Biochem 341:40-51

Du JX, Li YH, Lv JR (2001) Investigation on the chemiluminescence reaction of luminol- $\mathrm{H}_{2} \mathrm{O}_{2}-\mathrm{S}^{2-} / \mathrm{R}-\mathrm{SH}$ system. Anal Chim Acta 448:79-83

Evans CL (1967) The toxicity of hydrogen sulfide and other sulfides. J Exp Physiol 52:231-248

Ferrer L, de Armas G, Mir M, Estela JM, Cerdà V (2004) A multisyringe flow injection method for the automated determination of sulfide in waters using a miniaturized optical fiber spectrophotometer. Talanta 64:1119-1126

Fischer E (1883) Formation of methylene blue in response to hydrogen sulfide. Ber Dtsch Chem Ges 16:2234-2236

Furne J, Saeed A, Levitt MD (2008) Whole tissue hydrogen sulfide concentrations are orders of magnitude lower than presently accepted values. Am J Physiol Regul Integr Comp Physiol 295:1479-1485

García-Calzada M, Marbán G, Fuertes AB (1999) Potentiometric determination of sulphur in solid samples with a sulphide selective electrode. Anal Chim Acta 380:39-45

Ghadiri M, Kariminia H, RoostaAzad R (2013) Spectrophotometric determination of sulfide based on peroxidase inhibition by detection of purpurogallin formation. Ecotoxicol Environ Saf 91:117-121

Giuriati C, Cavalli S, Gorni A, Badocco D, Pastore P (2004) Ion chromatographic determination of sulfide and cyanide in real matrices by using pulsed amperometric detection on a silver electrode. J Chromatogr A 1023:105-112

Gohda S, Morishige K, Yamada N, Okatake M, Nishikawa Y (1986) Determination of sulfide ions in water by fluorescence quenching of mercuriofluoresceinates. Bunseki Kagaku 35:80-86

Gupta VK, Saleh TA (2013) Sorption of pollutants by porous carbon, carbon nanotubes and fullerene-An overview. Environ Sci Pollut Res 20:2828-2843

Gupta VK, Agarwal S, Saleh TA (2011a) Chromium removal by combining the magnetic properties of iron oxide with adsorption properties of carbon nanotubes. Water Res 45:2207-2212 
Gupta VK, Agarwal S, Saleh TA (2011b) Synthesis and characterization of alumina-coated carbon nanotubes and their application for lead removal. J Hazard Mater 185:17-23

Gupta VK, Jain R, Mittal A, Saleh TA, Nayak A, Agarwal S, Sikarwar S (2012) Photo-catalytic degradation of toxic dye amaranth on $\mathrm{TiO}_{2} / \mathrm{UV}$ in aqueous suspensions. Mater Sci Eng C 32:12-17

Gupta VK, Kumar R, Nayak A, Saleh TA, Barakat MA (2013) Adsorptive removal of dyes from aqueous solution onto carbon nanotubes: a review. Adv Colloid Interface Sci 193:24-34

Hannestad U, Margheri S, Sorbo B (1989) A sensitive gas chromatographic method for determination of protein associated sulfur. Anal Biochem 178:394-398

He Y, Zheng Y, Locke DC (2002) Differential pulse cathodic stripping voltammetric determination of nanomolar levels of dissolved sulfide applicable to field analysis of groundwater. Anal Chim Acta 459:209-217

Huang RF, Zheng XW, Qu YJ (2007) Highly selective electrogenerated chemiluminescence (ECL) for sulfide ion determination at multi-wall carbon nanotubes-modified graphite electrode. Anal Chim Acta 582:267-274

Jin Y, Wu H, Tian Y, Chen LH, Cheng JJ, Bi SP (2007) Indirect determination of sulfide at ultra-trace levels in natural waters by flow injection on-line sorption in a knotted reactor coupled with hydride generation atomic fluorescence spectrometry. Anal Chem 79:7176-7181

Kim K-H, Choi Y-J, Jeon E-C, Sunwoo Y (2005) Characterization of malodorous sulfur compounds in landfill gas. Atmos Environ 39:1103-1112

Kim K-H, Jeon E-C, Choi Y-J, Koo YS (2006) The emission characteristics and the related malodor intensities of gaseous reduced sulfur compounds (RSC) in a large industrial complex. Atmos Environ 40:4478-4490

Kuban V, Dasgupta PK, Marx JN (1992) Nitroprusside and methylene blue methods for silicone membrane differentiated flow injection determination of sulfide in water and wastewater. Anal Chem 64:36-43

Lawrence NS, Davis J, Compton RG (2000) Analytical strategies for the detection of sulfide: a review. Talanta 52:771-784

Lawrence NS, Deo RP, Wang J (2004) Electrochemical determination of hydrogen sulfide at carbon nanotube modified electrodes. Anal Chim Acta 517:131-137

Maya F, Estela JM, Cerd V (2007) Improving the chemiluminescence-based determination of sulphide in complex environmental samples by using a new, automated multi-syringe flow injection analysis system coupled to a gas diffusion unit. Anal Chim Acta 601:87-94

Pandey SK, Kim K-H (2009) A review of methods for the determination of reduced sulfur compounds (RSCs) in air. Environ Sci Technol 43:3020-3029

Pandey SK, Kim KH, Tang KT (2012) A review of sensor-based methods for monitoring hydrogen sulfide. Trend Anal Chem 32:87-99

Patnaik P (1999) A comprehensive guide to the hazardous properties of chemical substances, 2nd edn. Wiley, New York

Peng H, Cheng Y, Dai Ch, King AL, Predmore BL, Lefer DJ, Wang B (2011) A fluorescent probe for fast and quantitative detection of hydrogen sulfide in blood. Angew Chem Int Ed 50:9672-9675

Pouly F, Touraud E, Buisson JF, Thomas O (1999) An alternative method for the measurement of mineral sulphide in wastewater. Talanta 50:737-742
Rodriguez-Fernandez J, Costa JM, Pereiro R, Sanz-Medel A (1999) Simple detector for oral malodor based on spectrofluorimetric measurements of hydrogen sulphide in mouth air. Anal Chim Acta 398:23-31

Safavi A, Karimi MA (2002) Flow injection chemiluminescence determination of sulfide by oxidation with $\mathrm{N}$-bromosuccinimide and $N$-chlorosuccinimide. Talanta 57:491-500

Safavi A, Ramezani Z (1997) Kinetic spectrophotometric determination of trace of sulfide. Talanta 44:1225-1230

Saleh TA (2011) The influence of treatment temperature on the acidity of MWCNT oxidized by $\mathrm{HNO}_{3}$ or a mixture of $\mathrm{HNO}_{3} /$ $\mathrm{H}_{2} \mathrm{SO}_{4}$. Appl Surf Sci 257:7746-7751

Saleh TA (2015a) Isotherm, kinetic, and thermodynamic studies on $\mathrm{Hg}$ (II) adsorption from aqueous solution by silica-multiwall carbon nanotubes. Environ Sci Pollut Res 22:16721-16731

Saleh TA (2015b) Nanocomposite of carbon nanotubes/silica nanoparticles and their use for adsorption of $\mathrm{Pb}(\mathrm{II})$ : from surface properties to sorption mechanism. Desalination Water Treat. doi:10.1080/19443994.2015.1036784

Saleh TA, Gupta VK (2011) Functionalization of tungsten oxide into MWCNT and its application for sunlight-induced degradation of rhodamine B. J Colloid Interface Sci 362:337-344

Saleh TA, Gupta VK (2012a) Column with CNT/magnesium oxide composite for lead(II) removal from water. Environ Sci Pollut Res 19:1224-1228

Saleh TA, Gupta VK (2012b) Synthesis and characterization of alumina nano-particles polyamide membrane with enhanced flux rejection performance. Sep Purif Technol 89:245-251

Saleh TA, Gupta VK (2012c) Photo-catalyzed degradation of hazardous dye methyl orange by use of a composite catalyst consisting of multi-walled carbon nanotubes and titanium dioxide. J Colloid Interface Sci 371:101-106

Saleh TA, Agarwal S, Gupta VK (2011) Synthesis of MWCNT/MnO and their application for simultaneous oxidation of arsenite and sorption of arsenate. Appl Catal B 106:46-53

Saleh TA, AL-Saadi AA, Gupta VK (2014) Carbonaceous adsorbent prepared from waste tires: experimental and computational evaluations of organic dye methyl orange. J Mol Liquids 191:85-91

Siegel LM (1965) A direct microdetermination for sulfide. Anal Biochem 11:126-132

Silva MSP, da Silva IS, Abate G, Masini JC (2001) Spectrophotometric determination of acid volatile sulfide in river sediments by sequential injection analysis exploiting the methylene blue reaction. Talanta 53:843-850

Silva MSP, Galhardo CX, Masini JC (2003) Application of sequential injection-monosegmented flow analysis (SI-MSFA) to spectrophotometric determination of sulfide in simulated waters samples. Talanta 60:45-52

Spaziani MA, Tinani M, Carroll MK (1997) On-line determination of sulfide by the 'methylene blue method' with diode-laser-based fluorescence detection. Analyst 122:1555-1557

Spilker B, Randhahn J, Grabow H, Beikirch H, Jeroschewski P (2008) New electrochemical sensor for the detection of hydrogen sulfide and other redox active species. J Electroanal Chem 612:121-130

Tsai DM, Kumar AS, Zen J-M (2006) A highly stable and sensitive chemically modified screen-printed electrode for sulfide analysis. Anal Chim Acta 556:145-150

Watts SF (2000) The mass budgets of carbonyl sulfide, dimethyl sulfide, carbon disulfide and hydrogen sulfide. Atmos Environ 34:761-779 
Yang M, Zhang W, Zhou D, Zhao J, Tao S (2000) Fluorescence quenching of the sulfur anion-selective membrane-based photochemical sensitive. J Anal Chem 28:50-52

Yang X-F, Wang L, Xu H, Zhao M (2009) A fluorescein-based fluorogenic and chromogenic chemodosimeter for the sensitive detection of sulfide anion in aqueous solution. Anal Chim Acta 631:91-95
Yao W, Millero FJ (1996) Oxidation of hydrogen sulfide by hydrous $\mathrm{Fe}(\mathrm{III})$ oxides in seawater. Mar Chem 52:1-16

Zhang H, Xie Y, Wang P, Chen G, Liu R, Lam Y-W, Hu Y, Zhu Q, Sun $H$ (2015) An iminocoumarin benzothiazole-based fluorescent probe for imaging hydrogen sulfide in living cells. Talanta 135:149-154 